\title{
Multiple Factor Analysis of Depression and/or Anxiety in Patients with Acute Exacerbation Chronic Obstructive Pulmonary Disease
}

This article was published in the following Dove Press journal: International Journal of Chronic Obstructive Pulmonary Disease

Jian Long, ',2 Yao Ouyang,' Haizhen Duan, ${ }^{3}$ Zhongyong Xiang, ${ }^{2}$ Hongchang $\mathrm{Ma},{ }^{2}$ Mingliang Ju, ${ }^{4}$ Desheng Sun'

'Department of Respiratory Medicine, Affiliated Hospital of Zunyi Medical University, Zunyi City, Guizhou, People's Republic of China; ${ }^{2}$ Zunyi Fifth People's Hospital (Zunyi Mental Health Center), Zunyi City, Guizhou, People's Republic of China; ${ }^{3}$ Department of Emergency Medicine, Affiliated Hospital of Zunyi Medical University, Zunyi City, Guizhou, People's Republic of China; ${ }^{4}$ Shanghai Mental Health Center Affiliated to School of Medicine, Shanghai Jiao Tong University, Shanghai City, People's Republic of China

\section{Video Abstract}

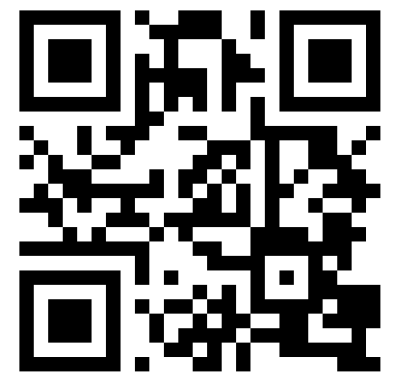

Point your SmartPhone at the code above. If you have a $Q R$ code reader the video abstract will appear. Or use: https://youtu.be/YDos4THvpao

Correspondence: Yao Ouyang Department of Respiratory Medicine, Affiliated Hospital of Zunyi Medical University, 149 Daliang Road, Zunyi City, Guizhou 563003, People's Republic of China

Tel +8613885216891

Email ouyangyaol I6@sohu.com
Objective: To reveal the risk factors, the symptom distribution characteristics, the clinical values of white blood cell counts (WBC counts), red blood cell distribution width (RDW), neutrophil-to-lymphocyte ratio (NLR), platelet-to-lymphocyte ratio (PLR) and monocyte-tolymphocyte ratio (MLR) in hospitalized patients with acute exacerbation of chronic obstructive pulmonary disease (AECOPD) combined with depression and/or anxiety.

Methods: The study included prospective cross-sectional and case-control studies, and was executed in the Affiliated Hospital of Zunyi Medical University, Guizhou, China. Previously diagnosed chronic obstructive pulmonary disease (COPD) patients who admitted to the hospital with AECOPD, patients with depression and/or anxiety, and healthy people were enrolled in the study. The Hamilton Rating Scales were used to assess all subjects, and the complete blood counts (CBC) were collected. Baseline data and clinical measurement data [spirometry, arterial blood gas analysis, and COPD evaluation test (the CAT scale)] from patients with AECOPD were collected. Results: Of the 307 patients with AECOPD included, 63.5\% (N=195) had depressive and/or anxiety symptoms, and $36.5 \%(\mathrm{~N}=112)$ had no symptoms. Sex, respiratory failure, number of comorbidities, number of acute exacerbations in the previous year and the CAT score were closely related to AECOPD combined with depression and/or anxiety $(p<0.05)$. The CAT scale score were the independent risk factor $(\mathrm{OR}=6.576,95 \% \mathrm{CI} 3.812-11.342)$ and significant predictor of AECOPD with depression and/or anxiety ( $\mathrm{AUC}=0.790,95 \%$ CI 0.740 -0.834 ); the patients with depression and/or anxiety were more severe and characteristic than the patients with AECOPD combined with depression and/or anxiety; RDW was associated with AECOPD with depression and/or anxiety ( $\mathrm{p}=0.020$, OR $1.212,95 \%$ CI1.03-1.426), and had certain clinical diagnostic value ( $\mathrm{AUC}=0.570,95 \% \mathrm{CI} 0.531-0.626$ ).

Conclusion: Depression and anxiety should not be ignored in patients with AECOPD. The severity and quality of life of COPD were closely related to the occurrence of depression and/or anxiety symptoms. In most cases, perhaps depression and anxiety in AECOPD are only symptoms and not to the extents of the diseases. RDW had clinical diagnostic value in AECOPD combined with depression and/or anxiety. NLR, PLR, MLR, and RDW may become the novel indicators for evaluating the degree of inflammation of AECOPD and deserve further research. Keywords: AECOPD, anxiety, depression, comorbidities, Hamilton Rating Scale, inflammatory markers, symptomatology

\section{Introduction}

Chronic obstructive pulmonary disease (COPD) is the most frequent respiratory disease in middle-aged and old people in both developing and developed countries. Up to now, COPD has become the third leading cause of death globally, with $6 \%$ of 
the total deaths caused by COPD. ${ }^{1}$ Depression and anxiety are more common in COPD, which are related to poor physical function, impaired health status and increased mortality, ${ }^{2,3}$ therefore are receiving more and more attentions from clinicians. In previous studies, the prevalence of depression and anxiety was 9-58\% among AECOPD patients. ${ }^{4-6}$ Moreover, the prevalence of depression and anxiety was shown to be higher in patients with severe COPD, with $37-71 \%$ prevalence of depression and $50-75 \%$ prevalence of anxiety. ${ }^{7}$ COPD patients with depression and anxiety often show more frequent acute exacerbations, longer hospital stays, worse quality of life, lower treatment compliance. ${ }^{8-11}$ It had been seen the profound influences of depression and anxiety on COPD from these researches. However, the diagnoses of psychiatric illnesses by respiratory clinicians are inadequate. Various tools for assessing COPD with depression and anxiety, such as the Beck Anxiety Inventory and Beck Depression Inventory, the Patient Health Questionnaire-9 (PHQ-9), the Hospital Anxiety and Depression Scale (HADS), etc., are considered by scholars as good tools. But it is not easy for clinicians to master. Especially, the face-to-face interview skill needed for psychiatric diagnosis, which is a big challenge for them.

COPD mainly manifests as inflammation in the lungs and affects different organs of the body. Systemic inflammation runs through the COPD patient's entire life cycle because of the disease, from the airways to the target organs and tissues throughout the body, and may be related to its comorbidities such as anxiety and depression. ${ }^{12}$ With the emergence of some new markers such as NLR and PLR, scholars have begun to study their clinical application values in various fields and found that they are related to mental diseases. ${ }^{13,14}$ Hence, it is necessary to find how these inflammatory markers change in COPD during acute exacerbation, and whether there are some potential associations with AECOPD with depression and/or anxiety. In the Global Initiative for Chronic Obstructive (GOLD 2019),${ }^{15}$ the identification of comorbidities is an important part of COPD management, especially for the prevention of acute exacerbations. Based on the negative impact of depression and anxiety comorbidities on the acute exacerbation of COPD, early assessment of depression and anxiety symptoms in patients with AECOPD will benefit the improvement of the treatment effect and prognosis of COPD. However, there is no consensus on the evaluation tools and diagnostic criteria of COPD with depression and anxiety in the guidelines. Therefore, we sought to help respiratory physicians optimize the diagnosis, management and treatment for AECOPD patients through this research, both the level of inflammatory markers, and the characteristics and the risks of psychological comorbidities, which was the main purpose of this study.

\section{Materials and Methods}

This study complies with the Helsinki Declaration and was approved by the Ethics Committee of Zunyi Medical University Hospital on December 13, 2018. Informed consent was obtained from all participants.

\section{Study Setting}

The prospective cross-sectional and case-control data were selected for analysis. All the enrolled subjects came from the Department of Respiratory, Physical Examination Center and Psychiatry of the Affiliated Hospital of Zunyi Medical University, Guizhou, China, from January 2019 to December 2019.

\section{Participants}

A total of the 689 participants, according to the inclusion and exclusion criteria: 307 patients with AECOPD aged 34-95 years, 91 patients with depression and/or anxiety between 14-75 years, and 95 healthy people between $40-84$ years were eventually included in the study (Figure 1).

\section{Inclusion and Exclusion Criteria}

All the 493 included subjects followed the principle of voluntary participation in this study, had clear awareness and language skills, and signed informed consent. Inclusion and exclusion criteria of the AECOPD patients: COPD exacerbations were defined as an acute worsening of respiratory symptoms that result in additional therapy; ${ }^{16-19}$ At least one spirometry test in the history of the patient had the presence of a post-bronchodilator forced expiratory volume in one second (FEV1)/forced vital capacity $(\mathrm{FVC})<0.70$ confirmed the presence of persistent airflow limitation, had cough and sputum caused by recurrent lower respiratory tract infections, dyspnea, or exposure to COPD risk factors. Those who had illnesses with severe heart, liver and kidney failure, or psychiatric disorders were excluded from the study. Inclusion and exclusion criteria of the depression and/or anxiety patients: Meets the diagnostic criteria for depression and anxiety in the Mental and Behavioral Disorders Classification (ICD-10). ${ }^{20}$ Those who had illnesses with acute or chronic respiratory diseases, hematological diseases, and other serious mental illnesses were excluded from the 
All the 689 participants were from the Affiliated Hospital of Zunyi

Medical University. 427 AECOPD patients came from the respiratory

department, 150 people came from physical examination center, 112

patients with depression and/or anxiety came from psychiatry.

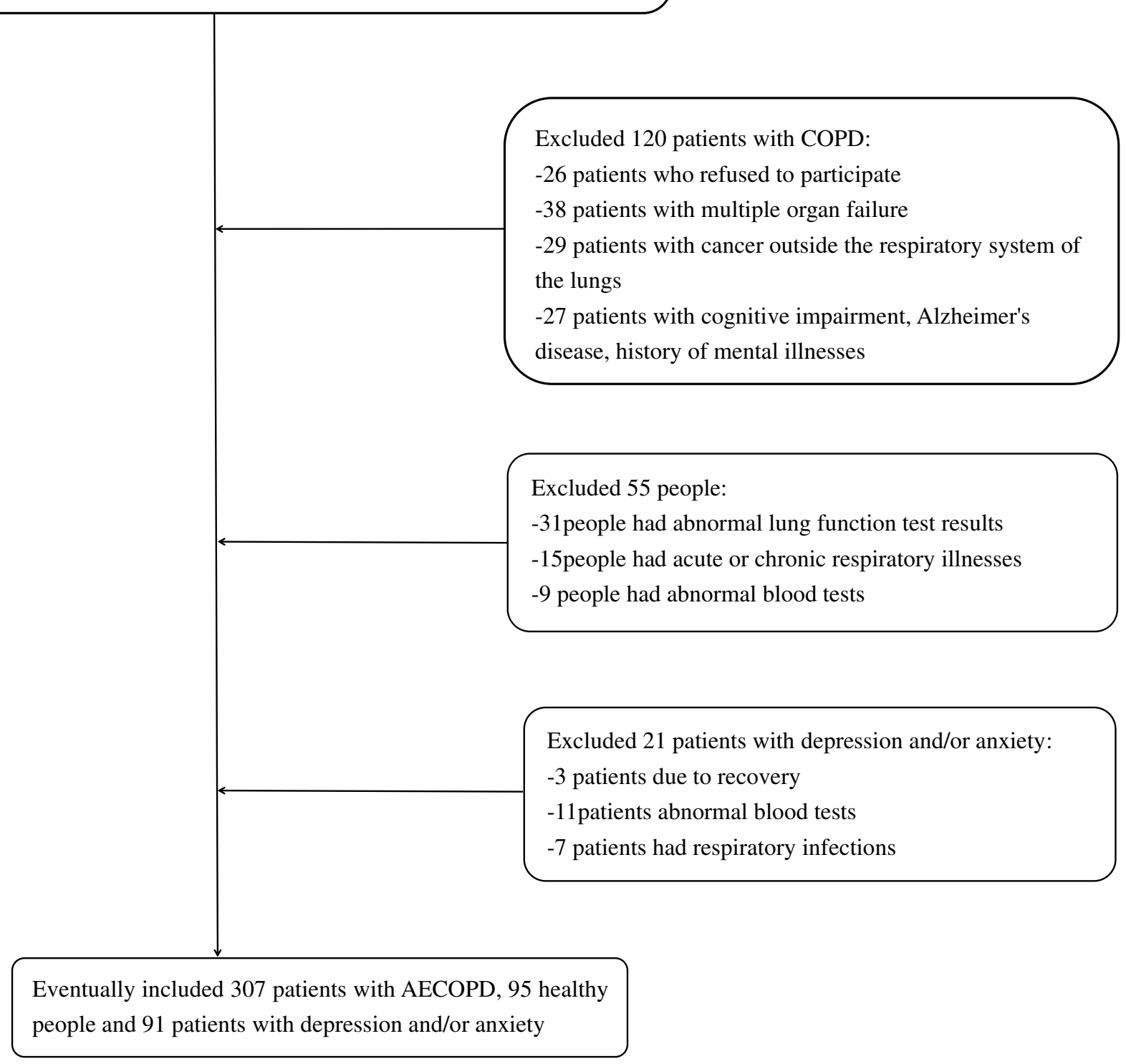

Figure I The consort diagram of the study.

study. Inclusion and exclusion criteria of the healthy people: Spirometry was normal, and there were no respiratory diseases, hematological diseases and mental illnesses in people over 40 years old.

\section{Data Collection Demographics}

General information form was used to collect baseline data for the 307 AECOPD patients. The contents include: sex, age, height, weight, smoking history, duration of illness, whether home oxygen therapy was carried out, whether glucocorticoid was inhaled, the number of acute exacerbations in the previous year, and the number of comorbidities.

\section{Physiological Variables}

Respiratory failure in patients with AECOPD was defined as: according to the results of arterial blood gas analysis, the patient's partial oxygen pressure during calm breathing is below $60 \mathrm{mmHg}$ in the state of no oxygen. ${ }^{21}$ The severity of airflow restriction was classified according to 
the GOLD rating: GOLD I, II, III, or IV depending on the post-bronchodilator FEV1/FVC as described in the GOLD (2019). ${ }^{15}$ Peripheral complete blood counts (CBC) of all included subjects were collected for WBC counts, RDW, NLR, PLR, and MLR. Neutrophil-tolymphocyte ratio: defined as the absolute value of neutrophils divided by the absolute value of lymphocytes. Platelet-to-lymphocyte ratio:defined as the absolute value of platelets divided by the absolute value of lymphocytes. Monocyte-to-lymphocyte ratio:defined as the absolute value of monocytes divided by the absolute value of lymphocytes.

\section{Hamilton Depression and Anxiety Rating Scale}

All the included subjects were assessed by the same clinician from Zunyi Mental Health Center using the Hamilton Depression and Anxiety Rating Scale. All items of the Hamilton Rating scales are scored with 5 grades of 0-4 points. The Hamilton Anxiety Rating Scale (HAMA) includes 14 items of anxiety and partial depression symptoms, involving two types of symptoms factors $\square$ psychic anxiety factor and somatic anxiety factor. The psychic anxiety factor include: anxiety mood, tension, fears, insomnia, difficulties in concentration and memory, depression mood, and behaviour during interview; and the somatic anxiety factor include seven systemic symptoms: muscle, sensory, cardiovascular, respiratory, gastrointestinal, genito-urinary and other autonomic nervous system symptoms, respectively. The score ranges from 0 to 56 and $\geq 14$, suggesting clinically significant anxiety symptoms. The Hamilton Depression Rating Scale (HAMD) is one of the most widely used depression assessment tools in the world, and the 24 item version we used has score from $0-76$ points, $>20$ points, indicating that there must be depression. The scale includes seven types of depression factors: anxiety/somatization (psychic anxiety, somatic anxiety, gastro-intestinal, general somatic symptoms, hypochondriasis, insight), weight (loss of weight), cognitive impairment (feeling of guilt, suicide, agitation, depersonalization and derealization, paranoid symptoms, obsessional symptoms), diurnal variation, retardation, sleep disorder (insomnia-early, insomniamiddle, insomnia-late), and sense of despair (helplessness, hopelessness, worthlessness). The HAMA and the HAMD have good internal consistency, Cronbach's $\alpha$ can reach more than 0.8 , and both of them can show good reliability and validity. $^{22,23}$

\section{CAT Assessment Scale}

The chronic obstructive pulmonary disease assessment test (CAT) is a short and easy to complete health test tool, which is used to help patients and their clinicians evaluate and quantify the symptoms and effects of COPD. There is a 5-level scoring method of 0-4 points, which can help us to understand the influence of chronic obstructive pulmonary disease on the health and quality of life of patients with COPD by asking the patients about 8 items, such as cough, expectoration, chest distress, sleep and exercise endurance. It has good sensitivity and reliability. ${ }^{24,25}$ The total score is $40,0-10$ points, $11-20$ points, $21-30$ points and $31-40$ points respectively represent mild, moderate, severe or very serious clinical symptoms. ${ }^{26}$

\section{Definitions}

\section{Definition of Depression and/or Anxiety in Patients with AECOPD}

$\mathrm{HAMA} \geq 14$ and/or HAMD $>20$ were defined as AECOPD with depression and/or anxiety.

\section{Definition of Variables}

Sex, smoking history, home oxygen therapy, inhaled glucocorticoids, number of comorbidities, the GOLD stages and respiratory failure were classified variables; Age, body mass index, duration of illness, number of acute exacerbations in the previous year, the CAT scale score, the Hamilton Depression and Anxiety Rating Scale score and the five inflammatory markers results were continuous variables.

\section{Statistical Analyses}

Statistical analysis was conducted using the SPSS 24.0 package program. Kolmogorov Smirnov test was used to test the normal distribution of the variables of the groups. The normal data were presented as mean $\pm \mathrm{SD}$; The nonnormally distributed data were presented as median and inter-quartile range $\left[\mathrm{P}_{25}-\mathrm{P}_{75}\right]$. The categorical data were described by rate and percentage. Two groups of continuous clinical variables were compared using Student's $t$ test and the Mann-Whitney $U$-test for the normal and non-normally distributed data, respectively. The data of the three groups and above of non normal distribution were tested by Kruskal-Wallis $H$-test. The categorical variables were tested by the chi-square test. Unadjusted logistic regression models were used to examine the effect of risk factors on AECOPD patients with clinically relevant levels of both anxiety and/or depressive symptomatology. Odds ratios 
(OR) and $95 \%$ confidence intervals $(95 \% \mathrm{CI})$ were derived. Risk factors with a $\mathrm{p}<0.10$ were identified as being eligible for the multivariable logistic regression model. Correlation analysis used Pearson or Spearman correlation analysis. The sensitivity, specificity and clinical diagnostic values of the inflammatory markers were analyzed using the ROC curve (receiver operating characteristic curve). The $\mathrm{p}<0.05$ was considered statistically significant.

\section{Results}

\section{Clinical Baseline Characteristics of AECOPD Patients}

Baseline clinical data of the asymptomatic AECOPD group and the AECOPD with depression and/or anxiety group were compared. Of the 307 AECOPD patients included in the study, $63.5 \%(\mathrm{~N}=195)$ had scores indicative of clinically significant levels of anxiety and/or depression and 36.5\% $(\mathrm{N}=112)$ had no symptoms, according to the results of the Hamilton Rating Scale. There were significantly increased percentage of females $(41.0 \%$ vs. $24.1 \%, \mathrm{p}=0.002)$, respiratory failure symptoms $(47.7 \%$ vs. $34.8 \%, \mathrm{p}=0.027)$, but decreased percentage of the patients with smoking histories (47.2\% vs.63.4\%, $\mathrm{p}=0.003$ ), and also, had more comorbidities $(\mathrm{p}=0.004)$ and more acute exacerbations $(\mathrm{p}=0.009)$ in the AECOPD patients with depression and/or anxiety compared with the counterpart. Especially, the CAT score of the AECOPD with depression and/or anxiety group was significantly increased than the without and had a particularly significant difference between them $(p=0.000)$. It was noted that the GOLD stages was no correlation with depression/or anxiety in the AECOPD patients with spirometry reports $(p=0.093)$. Otherwise, in the comparison of baseline for demographic characteristics on age $(\mathrm{p}=0.658)$, body mass index $(\mathrm{p}=0.833)$, duration of the illness $(\mathrm{p}=0.079)$, home oxygen therapy $(\mathrm{p}=0.059)$ and glucocorticoid inhalations $(\mathrm{p}=0.181)$, there were no statistically significant difference between the two AECOPD groups. (Table 1)

\section{Risk Factors Related to AECOPD with Depression and/or Anxiety Symptoms}

The chi-square test was used to test for statistically significant variables between the two groups of AECOPD groups from Table 1 to research the risk factors for depression and/or anxiety in AECOPD. The females were 2.190 times $(95 \%$ CI $1.304-3.678)$ more likely to suffer from depression and/or anxiety than males in AECOPD. The risk of depression and/or anxiety was 1.707 times (95\% CI
1.056-2.757) higher in AECOPD patients with respiratory failure than in those without. The AECOPD patients with more than one comorbidities had a 2.144 -fold $(95 \%$ CI 1.276-3.602) greater risk of depression and/or anxiety than those with none or only one. Compared with one or less acute exacerbations in the previous year, the AECOPD patients with two or more had a 1.572-fold (95\% CI 0.985-2.509) increased risk of depression and/ or anxiety. The CAT scores were 6.942 times (95\% CI 4.136-11.654) as severe and very severe as mild and moderate in AECOPD. In our study, it should be noted that the patients without smoking histories $(71.5 \%$, $\mathrm{N}=103$ ) had higher prevalence of depression and/or anxiety than those who had $(56.4 \%, \mathrm{~N}=92)(\mathrm{p}=0.004$, OR0.49, 95\% CI 0.308-0.800). This result showed that smoking had a protective effect on depression and anxiety. We speculated that in this study, the patients with depression and/or anxiety in AECOPD group were mostly female patients who never smoked, which led to this result. Next, it had been analyzed the correlation between smoking history and depression and/or anxiety in only the male patients with AECOPD, as can be seen from Table 2, there was no statistically significant difference $(\mathrm{p}=0.765)$ between the males who had not smoking histories and those who had in the prevalence of AECOPD with depression and/or anxiety $(59.5 \%, 56.9 \%$, respectively) (Table 2).

\section{Multivariable Analysis and Final Model for AECOPD with Depression and/or Anxiety Symptoms}

Sex, smoking history, respiratory failure, number of comorbidities, number of acute exacerbations in the previous year, the CAT score, illness years, and home oxygen therapy $(p<0.10)$ were identified as being eligible for the regression equation, and the binary logistic regression analysis was carried out. The goodness of fit Hosmer-Lemeshow test had a p-value of 0.796 indicating a good fit. However, only the CAT score entered the final model (OR6.576,95\% CI3.812-11.342), which was an independent risk factor for AECOPD with depression and/or anxiety (Table 3).

\section{Correlation and the Predicted Value of CAT Scale and AECOPD Combined with Depression and/or Anxiety}

In patients with AECOPD, the CAT score presented a positive correlation with the HAMA score and the 
Table I Comparison of Baseline Data Between Non-Symptom AECOPD Group and Depression and/or Anxiety AECOPD Group

\begin{tabular}{|c|c|c|c|c|}
\hline Characteristics & $\begin{array}{l}\text { Overall } \\
(N=307)\end{array}$ & $\begin{array}{l}\text { Depression and/or } \\
\text { Anxiety }(\mathrm{N}=195)\end{array}$ & $\begin{array}{l}\text { Non-Symptom } \\
(\mathrm{N}=\mid \text { I 2) }\end{array}$ & p value* \\
\hline $\begin{array}{l}\text { Sex }[n(\%)] \\
\text { Males } \\
\text { Females }\end{array}$ & $\begin{array}{l}200(65.1 \%) \\
107(34.9 \%)\end{array}$ & $\begin{array}{l}115(59.0 \%) \\
80(41.0 \%)\end{array}$ & $\begin{array}{l}85(75.9 \%) \\
27(24.1 \%)\end{array}$ & 0.002 \\
\hline $\begin{array}{l}\text { Age, years }(m \pm S D) \\
\text { Body mass index, } \mathrm{kg} / \mathrm{m}^{2}(\mathrm{~m} \pm \mathrm{SD})\end{array}$ & $\begin{array}{l}68.5 \pm 10.6 \\
21.5 \pm 3.6\end{array}$ & $\begin{array}{l}68.3 \pm 10.3 \\
21.5 \pm 3.4\end{array}$ & $\begin{array}{l}68.8 \pm 11.0 \\
21.6 \pm 3.9\end{array}$ & $\begin{array}{l}0.658 \\
0.833\end{array}$ \\
\hline $\begin{array}{l}\text { Smoking history }[\mathrm{n}(\%)] \\
\text { Never } \\
\text { Yes }\end{array}$ & $\begin{array}{l}144(46.9 \%) \\
163(53.1 \%)\end{array}$ & $\begin{array}{l}103(52.8 \%) \\
92(47.2 \%)\end{array}$ & $\begin{array}{l}4 \mathrm{I}(36.6 \%) \\
7 \mathrm{I}(63.4 \%)\end{array}$ & 0.003 \\
\hline $\begin{array}{l}\text { Duration of the IIIness, years } M\left(P_{25}\right. \\
\left.-P_{75}\right)\end{array}$ & $5(3-10)$ & $6(3-10)$ & $4(1-10)$ & 0.079 \\
\hline $\begin{array}{l}\text { Comorbidities[n(\%)] } \\
\quad \leq 1 \\
>1\end{array}$ & $\begin{array}{l}201(65.4 \%) \\
106(34.6 \%)\end{array}$ & $\begin{array}{l}116(59.5 \%) \\
79(40.5 \%)\end{array}$ & $\begin{array}{l}85(75.9 \%) \\
27(24.1 \%)\end{array}$ & 0.004 \\
\hline $\begin{array}{l}\text { Inhaled glucocorticoids [n(\%)] } \\
\text { Yes } \\
\text { No }\end{array}$ & $\begin{array}{l}37(12.1 \%) \\
270(87.9 \%)\end{array}$ & $\begin{array}{l}27(13.8 \%) \\
168(86.2 \%)\end{array}$ & $\begin{array}{l}10(8.9 \%) \\
102(91.1 \%)\end{array}$ & 0.181 \\
\hline $\begin{array}{l}\text { Home oxygen therapy }[n(\%)] \\
\text { Yes } \\
\text { No }\end{array}$ & $\begin{array}{l}51(16.6 \%) \\
256(83.4 \%)\end{array}$ & $\begin{array}{l}38(19.5 \%) \\
157(80.5 \%)\end{array}$ & $\begin{array}{l}13(11.6 \%) \\
99(88.4 \%)\end{array}$ & 0.059 \\
\hline $\begin{array}{l}\text { Number of } A E s \text { in the previous year }(n) \\
{\left[M\left(P_{25}-P_{75}\right)\right]}\end{array}$ & $2(I-3)$ & $2(I-3)$ & I $(0.25-3)$ & 0.009 \\
\hline $\begin{array}{l}\text { Respiratory failure }[n(\%)] \\
\text { Yes } \\
\text { No }\end{array}$ & $\begin{array}{l}132(43.0 \%) \\
175(57.0 \%)\end{array}$ & $\begin{array}{l}93(47.7 \%) \\
102(52.3 \%)\end{array}$ & $\begin{array}{l}39(34.8 \%) \\
73(65.2 \%)\end{array}$ & 0.027 \\
\hline CAT score $(m \pm S D)$ & $21.9 \pm 9.2$ & $24.5 \pm 8.0$ & $15.2 \pm 8 . \mid$ & 0.000 \\
\hline $\begin{array}{l}\text { GOLD stages }[\mathrm{n}(\%)] \\
\text { I } \\
\text { II } \\
\text { III } \\
\text { IV } \\
\text { Miss }\end{array}$ & $\begin{array}{l}32(10.4 \%) \\
96(31.3 \%) \\
71(23.1 \%) \\
31(10.1 \%) \\
77(25.1 \%)\end{array}$ & $\begin{array}{l}17(8.7 \%) \\
58(29.7 \%) \\
42(21.5 \%) \\
24(12.3 \%) \\
54(27.8 \%)\end{array}$ & $\begin{array}{l}15(13.4 \%) \\
38(33.9 \%) \\
29(25.9 \%) \\
7(6.3 \%) \\
23(20.5 \%)\end{array}$ & 0.093 \\
\hline $\begin{array}{l}\text { HAMA score }(m \pm S D) \\
\text { HAMD score }(m \pm S D)\end{array}$ & $\begin{array}{l}19.3 \pm 11.0 \\
12.6 \pm 9.5\end{array}$ & $\begin{array}{l}25.8 \pm 8.3 \\
\mid 7.1 \pm 9.0\end{array}$ & $\begin{array}{l}8.1 \pm 3.5 \\
4.9 \pm 3.5\end{array}$ & $\begin{array}{l}0.000 \\
0.000\end{array}$ \\
\hline
\end{tabular}

Notes: The measurement data were presented as mean \pm standard $(\mathrm{m} \pm \mathrm{SD})$ deviation for the normally distributed variables or as median and interquartile range $\left[\mathrm{M}\left(\mathrm{P}_{25}-\mathrm{P}_{75}\right)\right]$ for the non-normally distributed variables. The categorical data were described by rate and percentage. *Statistical differences were evaluated between the non-symptom AECOPD and depressive and/or anxious AECOPD patients.

Abbreviations: AECOPD, acute exacerbation of chronic obstructive pulmonary disease; CAT, the COPD assessment test; GOLD, Global Initiative for Chronic Obstructive Lung Disease; HAMA, the Hamilton Anxiety Rating Scale; HAMD, the Hamilton Depression Rating Scale; Smoking history: Yes, current or previous smoking; Never, had not smoking histories; AEs, acute exacerbations.

HAMD score. The correlation coefficient $\left(\mathrm{r}^{2}\right)$ with the HAMA score was $0.586(\mathrm{p}=0.000)$, and with the HAMD score was $0.587(\mathrm{p}=0.000)$ (Figures 2 and 3 ). The predicted value of the CAT scale for depression and/or anxiety in patients with AECOPD was evaluated using ROC curve analysis. The AUC was 0.790 (95\% CI $0.740-0.834)$, and the cut-off value was 20 (sensitivity $=74.36 \%$, specificity $=70.54 \%$ ) (Figure $4 \mathrm{~A})$. 
Table 2 Association Between Characteristics and AECOPD Patients with Concomitant Depression and Anxiety

\begin{tabular}{|c|c|c|c|c|c|}
\hline Characteristics $[n(\%)]$ & $\begin{array}{l}\text { Total } \\
(\mathrm{N}=307)\end{array}$ & $\begin{array}{l}\text { Anxiety and/or Depression } \\
(\mathrm{N}=195)\end{array}$ & $\chi^{2}$ & $\mathbf{p}^{*}$ value & OR $(95 \% \mathrm{Cl})$ \\
\hline \multicolumn{6}{|l|}{ Sex } \\
\hline Males & 200 (65.1\%) & II 15 (57.5\%) & 8.968 & 0.03 & $2.190(1.304-3.678)$ \\
\hline Females & 107 (34.9\%) & $80(74.8 \%)$ & & & \\
\hline \multicolumn{6}{|l|}{ Smoking history } \\
\hline Never & 144 (46.9\%) & 103 (71.5\%) & 8.366 & 0.004 & $0.496(0.308-0.800)$ \\
\hline Yes & $163(53.1 \%)$ & $92(56.4 \%)$ & & & \\
\hline Men (Never) & $42(21 \%)$ & $25(59.5 \%)$ & 0.089 & 0.765 & $0.900(0.45 I-1.798)$ \\
\hline Men (Yes) & 158 (79\%) & 90 (56.9\%) & & & \\
\hline \multicolumn{6}{|l|}{ Respiratory failure } \\
\hline Yes & $132(43.0 \%)$ & 93 (70.5\%) & 4.808 & 0.028 & 1.707 (I.056-2.757) \\
\hline No & 175 (57.0\%) & 102 (58.3\%) & & & \\
\hline \multicolumn{6}{|l|}{ Comorbidities } \\
\hline$\leq 1$ & 201 (65.4\%) & 116 (57.7\%) & 8.470 & 0.004 & $2.144(1.276-3.602)$ \\
\hline$>1$ & $106(34.6 \%)$ & 79 (74.5\%) & & & \\
\hline \multicolumn{6}{|l|}{$\begin{array}{l}\text { Number of AEs in the } \\
\text { previous year }\end{array}$} \\
\hline$\leq 1$ & I 48 (48.2\%) & $86(58.1 \%)$ & 3.609 & 0.057 & $1.572(0.985-2.509)$ \\
\hline$>1$ & 159 (5I.8\%) & $109(68.6 \%)$ & & & \\
\hline \multicolumn{6}{|l|}{ CAT score } \\
\hline Mild-Moderate & $129(42.0 \%)$ & $50(38.8 \%)$ & 58.853 & 0.000 & $6.942(4.136-11.654)$ \\
\hline Severe-very severe & $178(58.0 \%)$ & I 45 (8I.4\%) & & & \\
\hline
\end{tabular}

Notes: The data were described by rate and percentage. *Statistical differences were evaluated between the non-symptom AECOPD and depressive and/ or anxious AECOPD patients.

Abbreviations: Smoking history: Yes, current or previous smoking; Never, had not smoking histories; Men (Yes), current or former smoking men; Men (Never), men who had not smoking histories; AEs, acute exacerbations; CAT, the COPD Assessment Test.

Table 3 Multivariable Analysis and Final Model for Association Between Depressive and/or Anxious Symptomatology and Risk Factors in Patients with AECOPD

\begin{tabular}{|l|l|l|l|l|}
\hline \multicolumn{2}{|l|}{ Multivariable Model } & \multicolumn{2}{l|}{ Final Multivariable Model } \\
\hline Factors & Odds Ratio $(95 \%$ Cl) & p-value & Odds Ratio (95\% CI) & p-value* \\
\hline Sex & $1.431(0.629-3.255)$ & 0.393 & & \\
Smoking history & $0.583(0.272-1.25 I)$ & 0.166 & & \\
Respiratory failure & $1.321(0.75 I-2.326)$ & 0.334 & & \\
Comorbidities & $1.818(0.999-3.310)$ & $0.05 I$ & & 0.000 \\
Number of AEs in the previous year & $1.091(0.630-1.889)$ & 0.757 & & \\
CAT score & $6.576(3.812-11.342)$ & 0.000 & $6.576(3.812-11.342)$ & \\
Illness years & $1.087(0.490-2.4 I I)$ & 0.838 & & \\
Home oxygen therapy & $1.398(0.606-3.187)$ & 0.438 & & \\
\hline
\end{tabular}

Notes: We put $p<0.10$ variables: sex, smoking history, respiratory failure, number of common diseases, number of acute exacerbations in the previous year, CAT score, duration of Illness, and family oxygen therapy were included in the regression equation. The goodness of fit HosmerLemeshow test had a $\mathrm{p}$ value 0.769 indicating a good fit. *Statistical differences were evaluated into the final multivariable model.

\section{Symptom Distribution Characteristics of AECOPD with Depression and/or Anxiety}

After comparing the HAMA between the depression and/ or anxiety group and the AECOPD combined depression and/or anxiety group, there were significant statistical differences in the HAMA total score, psychic anxiety factor and somatic anxiety factor, the former showed higher levels of clinical anxiety symptoms $(p=0.000)$. (Table 4$)$. 


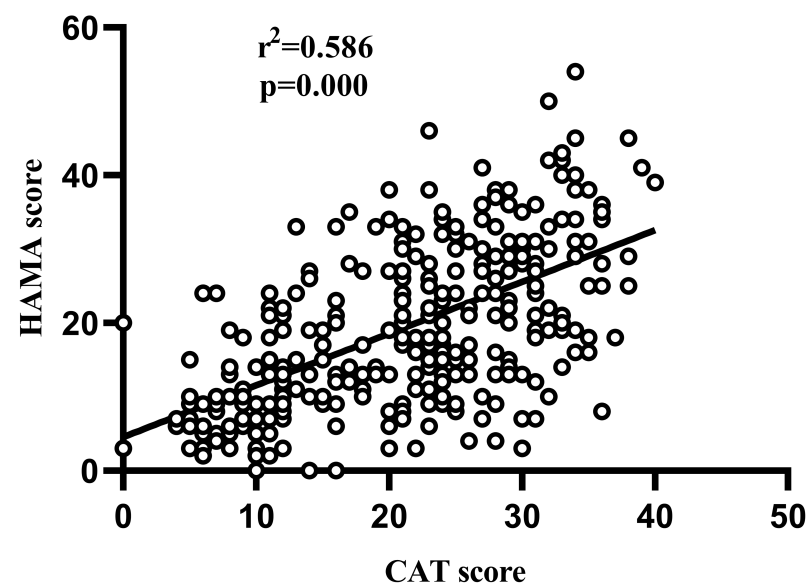

Figure 2 Correlation between the CAT scale score and the HAMA score.

Next, the HAMD was compared between the two groups. The HAMD total score, anxiety/somatization factor, cognitive impairment factor, diurnal variation factor, retardation factor, sleep disorder factor, the depression and/or anxiety group scored higher and showed characteristic depression symptoms $(\mathrm{p}=0.000)$. However, as for the loss of weight, AECOPD combined with depression and/or anxiety scored higher $(\mathrm{p}=0.033)$. Finally, in the sense of despair factor comparison, the difference between the two groups was not statistically significant $(\mathrm{p}=0.194)$ (Tables 5).

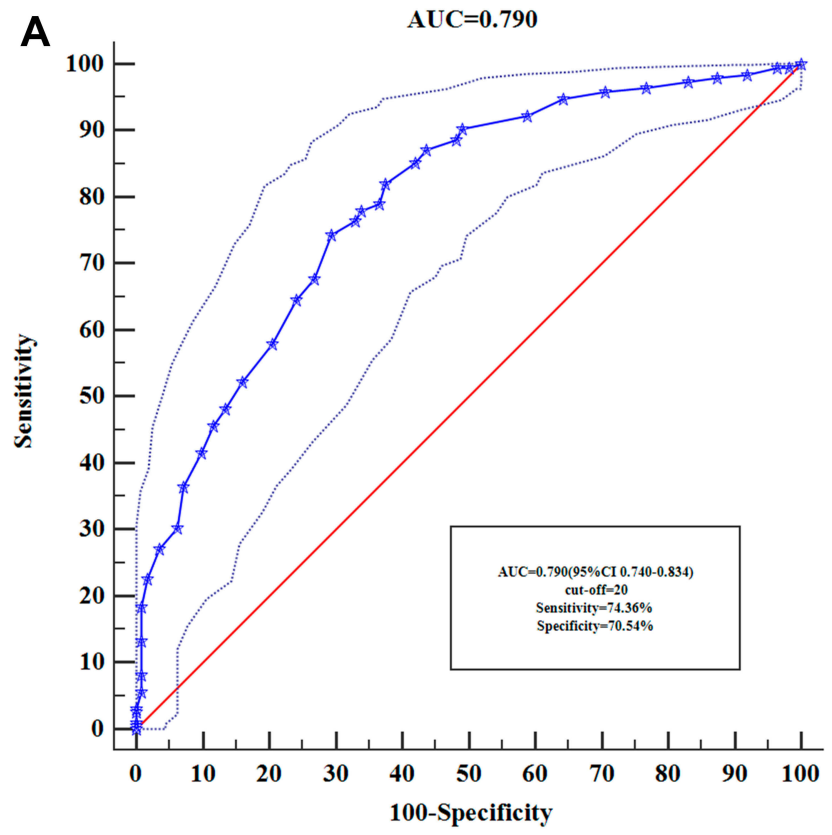

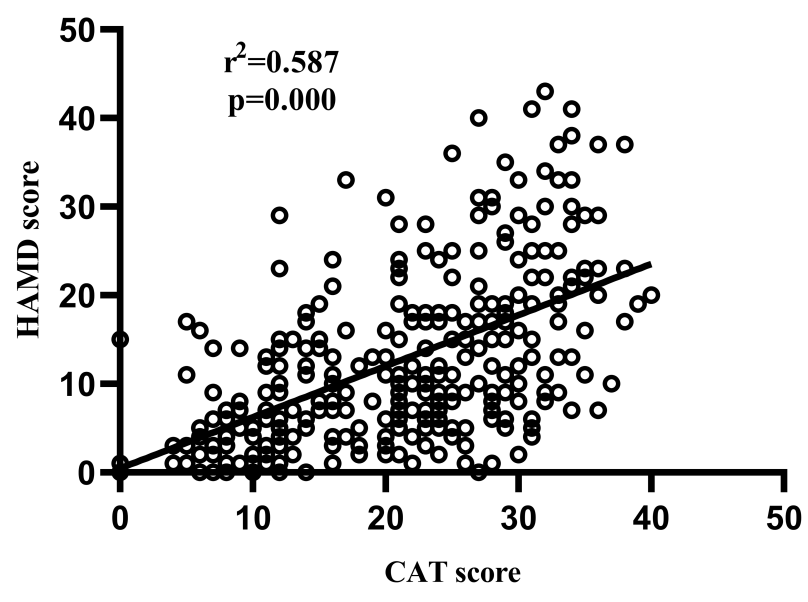

Figure 3 Correlation between the CAT scale score and the HAMD score.

\section{Comparison of the Inflammation Markers} Among the Healthy Control Group, Depression and/or Anxiety Group, Asymptomatic AECOPD Group, and AECOPD with Depression and/or Anxiety Group

In the included healthy control group ( $\mathrm{N}=95$, males 72 , females23, average age $59.2 \pm 9.5$ years), depression and anxiety group ( $\mathrm{N}=91$, males 23 , females 68 , average age $44.8 \pm 16.0$ years), asymptomatic AECOPD group ( $\mathrm{N}=112$, males85,

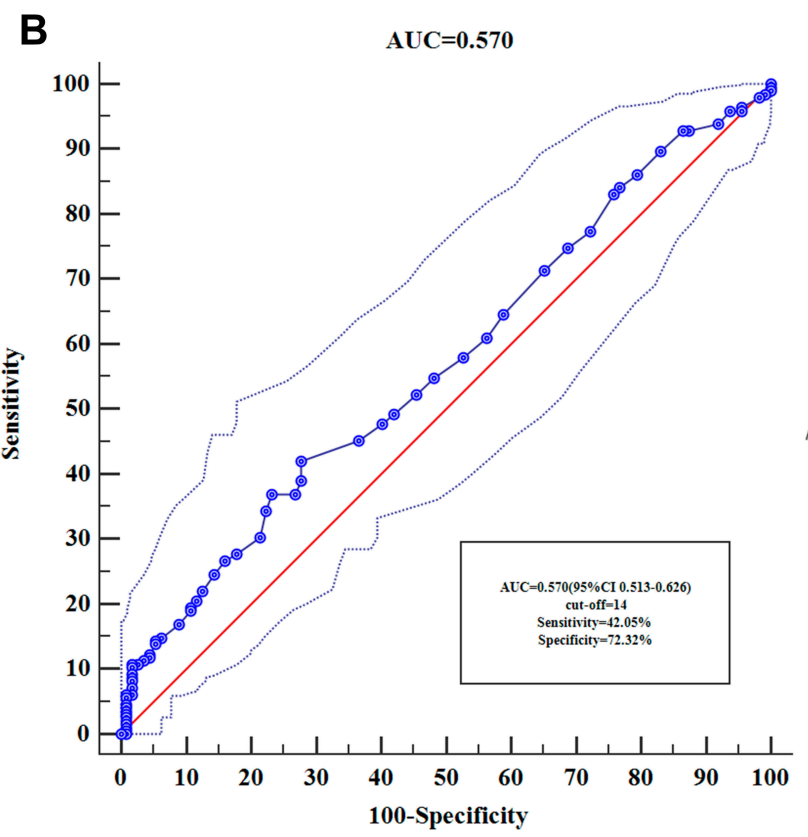

Figure 4 (A) ROC curve of the CAT scale score in diagnosis of the AECOPD with depression and/or anxiety. (B) ROC curve of red blood cell distribution width in diagnosis of the AECOPD with depression and/or anxiety. 
Table 4 Comparison of HAMA Between Depression and/or Anxiety Group and AECOPD with Depression and/or Anxiety Group

\begin{tabular}{|l|l|l|}
\hline Group & $\begin{array}{l}\text { Depression and/or } \\
\text { Anxiety Group } \\
\text { (N=9 I) }\end{array}$ & $\begin{array}{l}\text { AECOPD with } \\
\text { Depression and/or } \\
\text { Anxiety Group (N=195) }\end{array}$ \\
\hline HAMA score & $35.89 \pm 6.95$ & $25.83 \pm 8.35$ \\
\cline { 2 - 3 } $\begin{array}{l}\text { t value } \\
\text { P value * }\end{array}$ & \multicolumn{2}{|c|}{$\begin{array}{l}10.667 \\
0.000\end{array}$} \\
\hline $\begin{array}{l}\text { HAMA psychic } \\
\text { anxiety factor } \\
\text { t value } \\
\text { P value* }\end{array}$ & $20.66 \pm 4.01$ & $13.15 \pm 5.12$ \\
\cline { 2 - 3 } HAMA somatic & $15.23 \pm 5.03$ & 13.45 \\
anxiety factor & \multicolumn{2}{|c|}{0.000} \\
\cline { 2 - 3 } $\begin{array}{l}\text { t value } \\
\text { P value* }\end{array}$ & \multicolumn{2}{|c|}{3.868} \\
\hline
\end{tabular}

Notes: Data were presented as mean \pm standard deviation. HAMA's psychic anxiety factor include: anxiety mood, tension, fears, insomnia, difficulties in concentration and memory, depression mood and behaviour during interview; HAMA's somatic anxiety factor include seven systemic symptoms: muscle, sensory, cardiovascular, respiratory, gastro-intestinal, genito-urinary and other autonomic nervous system symptoms. * Statistical differences were evaluated between the depression and/or anxiety group and the AECOPD with depression and/or anxiety group.

females 27 , average age $68.8 \pm 11.0$ years), AECOPD combined depression and/or anxiety group $(\mathrm{N}=195$, males115, females 80 , average age $68.3 \pm 10.3$ years), the five inflammatory markers were compared among them. WBC counts, RDW, NLR, PLR, MLR had significant statistical differences among the four groups $(\mathrm{p}=0.000)$ (Table 6). Next, these inflammatory markers were compared within the groups. WBC counts, NLR, PLR, MLR, and RDW of the two AECOPD groups were significantly different from those the healthy control group and the depression and anxiety group $(\mathrm{p}<0.01)$ (Figures 5-9). Otherwise, the AECOPD with depression and/or anxiety group had higher RDW values than the asymptomatic AECOPD group $(\mathrm{p}<0.05)$ (Figure 6); PLR values of the depression and/or anxiety group were higher than that of the healthy control group $(\mathrm{p}<0.01)$ (Figure 8$)$.

\section{Correlation and the Clinical Diagnostic Value of RDW and AECOPD Combined with Depression and/or Anxiety}

In the AECOPD patients with depression and/or anxiety, RDW presented a positive correlation with the HAMA score and the HAMD score, the correlation coefficient $\left(\mathrm{r}^{2}\right)$ with the HAMA score was $0.116(\mathrm{p}=0.042)$, and with the HAMD score was $0.156(\mathrm{p}=0.006)$ (Figures 10
Table 5 Comparison of HAMD Between Depression and/or Anxiety Group and AECOPD with Depression and/or Anxiety Group

\begin{tabular}{|c|c|c|}
\hline Group & $\begin{array}{l}\text { Depression and/ } \\
\text { or Anxiety } \\
\text { Group }(\mathbf{N}=91)\end{array}$ & $\begin{array}{l}\text { AECOPD with } \\
\text { Depression and/or } \\
\text { Anxiety Group }(\mathrm{N}=195)\end{array}$ \\
\hline \multicolumn{3}{|l|}{ HAMD score } \\
\hline \multirow{3}{*}{$\begin{array}{l}\text { Rank mean value } \\
z \text { value } \\
P \text { value* }\end{array}$} & 189.98 & 121.81 \\
\hline & & -6.497 \\
\hline & & 0.000 \\
\hline \multicolumn{3}{|c|}{ Anxiety/somatization } \\
\hline \multirow{3}{*}{$\begin{array}{l}\text { Rank mean value } \\
\text { z value } \\
\text { P value* }\end{array}$} & 181.17 & 125.92 \\
\hline & & -5.293 \\
\hline & & 0.000 \\
\hline \multicolumn{3}{|l|}{ Loss of weight } \\
\hline \multirow{3}{*}{$\begin{array}{l}\text { Rank mean value } \\
z \text { value } \\
P \text { value* }\end{array}$} & 134.00 & 147.93 \\
\hline & & -2.137 \\
\hline & & 0.033 \\
\hline \multicolumn{3}{|c|}{ Cognitive impairment } \\
\hline \multirow{3}{*}{$\begin{array}{l}\text { Rank mean value } \\
z \text { value } \\
P \text { value* }\end{array}$} & 198.66 & 117.76 \\
\hline & & -8.174 \\
\hline & & 0.000 \\
\hline \multicolumn{3}{|l|}{ Diurnal variation } \\
\hline \multirow{3}{*}{$\begin{array}{l}\text { Rank mean value } \\
\text { z value } \\
P \text { value* }\end{array}$} & $|80.4|$ & 126.27 \\
\hline & & -8.954 \\
\hline & & 0.000 \\
\hline \multicolumn{3}{|l|}{ Retardation } \\
\hline \multirow{3}{*}{$\begin{array}{l}\text { Rank mean value } \\
z \text { value } \\
\text { P value* }\end{array}$} & 177.46 & 127.65 \\
\hline & & -4.802 \\
\hline & & 0.000 \\
\hline \multirow{3}{*}{$\begin{array}{l}\text { Sleep disorder } \\
\text { Rank mean value } \\
\text { z value } \\
\text { P value* }\end{array}$} & 178.55 & 127.14 \\
\hline & & -5.066 \\
\hline & & 0.000 \\
\hline \multirow{3}{*}{$\begin{array}{l}\text { Sense of despair } \\
\text { Rank mean value } \\
\text { Z value } \\
P \text { value }\end{array}$} & 134.29 & 147.80 \\
\hline & & -1.300 \\
\hline & & 0.194 \\
\hline
\end{tabular}

Notes: The data of HAMD were non-normal distribution. The Mann-Whitney U-test was used to compare the two groups. HAMD includes seven types of depression factors: anxiety/somatization (psychic anxiety, somatic anxiety, gastro-intestinal, general somatic symptoms, hypochondriasis, insight), weight (loss of weight), cognitive impairment (feeling of guilt, suicide, agitation, depersonalization and derealization, paranoid symptoms, obsessional symptoms), diurnal variation, retardation, sleep disorder (insomnia-early, insomnia-middle, Insomnia-late), and sense of despair (helplessness, hopelessness, worthlessness). *Statistical differences were evaluated between the depression and/or anxiety group and the AECOPD with depression and/or anxiety group. 
Table 6 Comparison of the Inflammatory Markers Between the Four Groups

\begin{tabular}{|l|l|l|l|l|l|}
\hline Group & WBC Counts & RDW & NLR & PLR & MLR \\
\hline A $(\mathrm{N}=95)$ & $6.16 \pm 1.25$ & $13.04 \pm 1.12$ & $2.04 \pm 0.73$ & $110.00 \pm 37.16$ & $0.23 \pm 0.07$ \\
$\mathrm{~B}(\mathrm{~N}=91)$ & $6.54 \pm 1.90$ & $13.02 \pm 1.17$ & $2.19 \pm 1.21$ & $127.79 \pm 52.01$ & $0.24 \pm 0.09$ \\
$\mathrm{C}(\mathrm{N}=112)$ & $7.77 \pm 3.56$ & $13.70 \pm 1.40$ & $5.21 \pm 4.70$ & $204.19 \pm 124.26$ & $0.53 \pm 0.36$ \\
$\mathrm{D}(\mathrm{N}=195)$ & $8.00 \pm 3.27$ & $14.17 \pm 1.78$ & $6.35 \pm 8.65$ & $226.83 \pm 219.02$ & $0.56 \pm 0.39$ \\
f value & 12.174 & 18.761 & 16.856 & 17.259 & 41.377 \\
P $^{*}$ value & 0.000 & 0.000 & 0.000 & 0.000 & 0.000 \\
\hline
\end{tabular}

Notes: Data were presented as mean \pm standard deviation. A, the healthy control group; B, the depression and/or anxiety group; C, the non-symptom AECOPD group; D, the AECOPD with depression and/or anxiety group. *Statistical differences were evaluated among the the four groups (A, B, C, D).

and 11). The diagnostic value of RDW was evaluated using ROC curve analysis. The AUC was $0.570(95 \%$ CI $0.513-0.626$ ), and the cut-off value was 14 (sensitivity $=42.05 \%$, specificity $=72.32 \%)($ Figure $4 B)$.

\section{Discussion}

Despite depression and anxiety are frequent comorbidities of COPD, the literatures on risk factors, symptoms and inflammatory markers to date are limited to investigating. To the best of our knowledge, this was the first study on the characteristics and the novel inflammatory markers between the AECOPD patients with depression and/or anxiety and the patients with depression and/or anxiety in China. The pathophysiology of depression and anxiety in COPD is complex and may be explained by multiple risk factors, systemic inflammation, and response to special symptoms of COPD. Of the 307 AECOPD patients

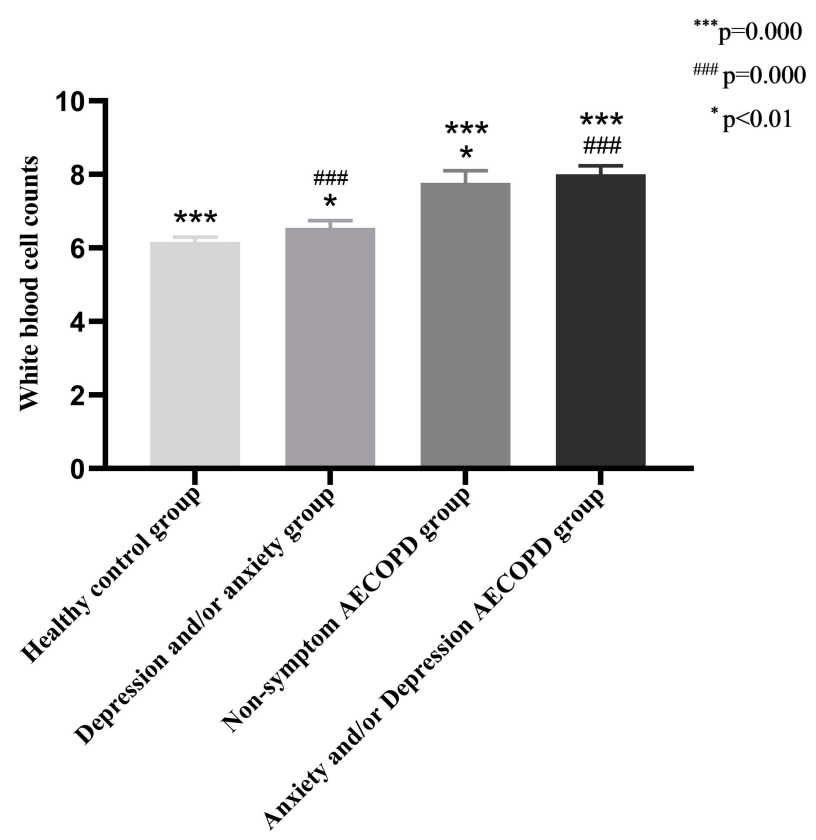

Figure 5 Comparison among the four groups of white blood cell counts. enrolled, more than half (63.7\%) had clinically significant levels of depression and/or anxiety symptoms. Clinicians interview skills, different assessment tools, and the severity of the disease included in COPD patients can show different prevalence and risk factors. Consistent with the studies of most scholars, ${ }^{27-30}$ women are susceptible to the development of depression and/or anxiety, both in the general population and in AECOPD. On the one hand, it is related to female sex hormone secretion and overreaction to social stress events; ${ }^{30}$ On the other hand, due to severe breathing difficulties, women's subjective feelings about the low social function and poor quality of life are stronger than men's, which may be one of the reasons for women's depression. ${ }^{28}$ Respiratory failure, the number of acute exacerbations in the previous year, and the CAT score representing symptoms and quality of life of COPD were strongly related to depression and/or

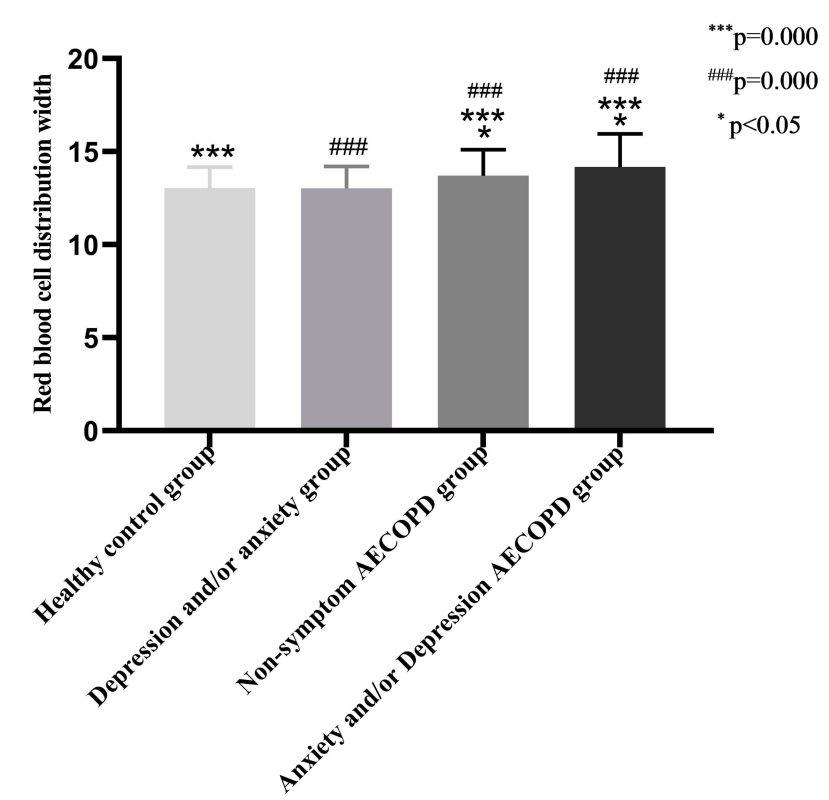

Figure 6 Comparison among the four groups of red blood cell distribution width. 


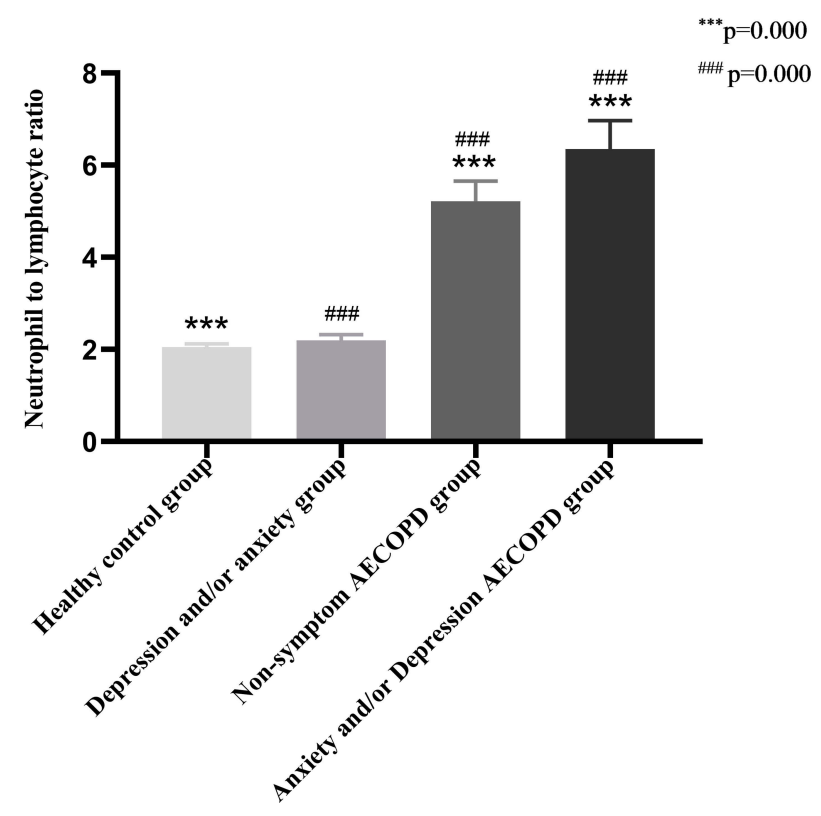

Figure 7 Comparison among the four groups of neutrophil-to-lymphocyte ratio.

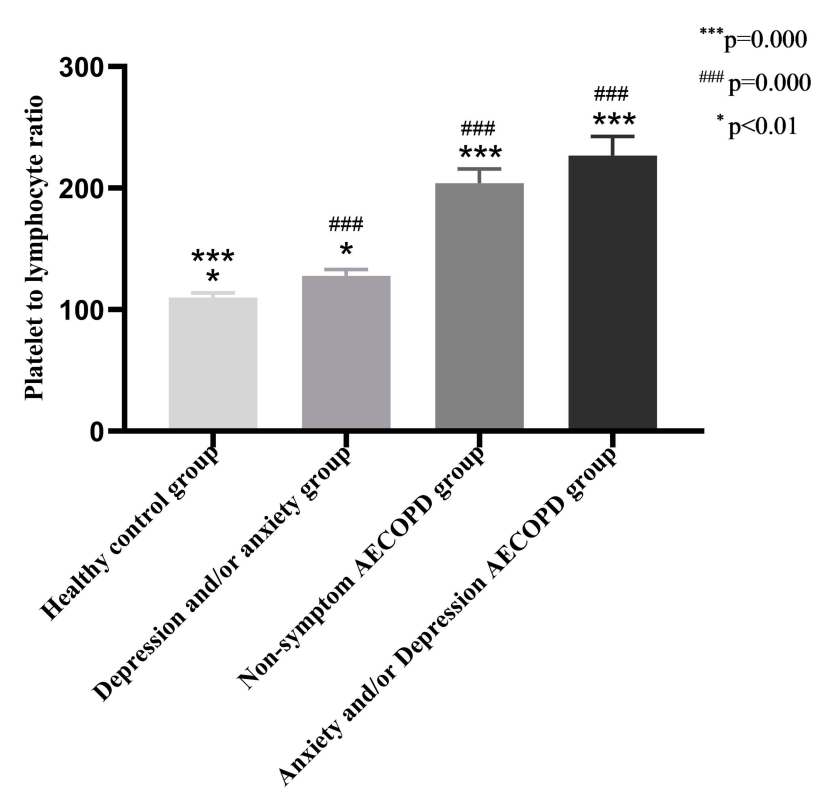

Figure 8 Comparison among the four groups of platelet-to-lymphocyte ratio.

anxiety in COPD. These evidences had been fully proved and elaborated by many scholars ${ }^{11,31-38}$ and was further confirmed in our study. The CAT score was positively correlated with the HAMA $\left(\mathrm{r}^{2}=0.586\right)$ and HAMD $\left(\mathrm{r}^{2}=0.587\right)$ scores (Figures 2 and 3$)$, and was the important predictor in AECOPD combined with depression and/or anxiety (AUC $=0.790,95 \%$ CI $0.740-0.834$ ) (Figure 4A). COPD is negatively impacted by multiple comorbid diseases, COPD itself is one of the most important comorbidities that adversely affects the outcome of those chronic

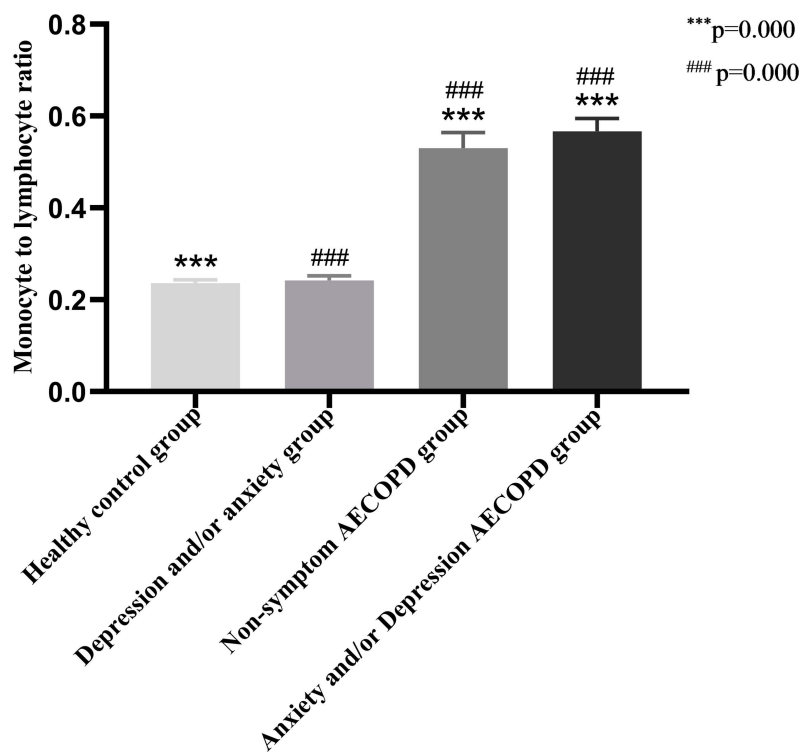

Figure 9 Comparison among the four groups of monocyte-to-lymphocyte ratio.

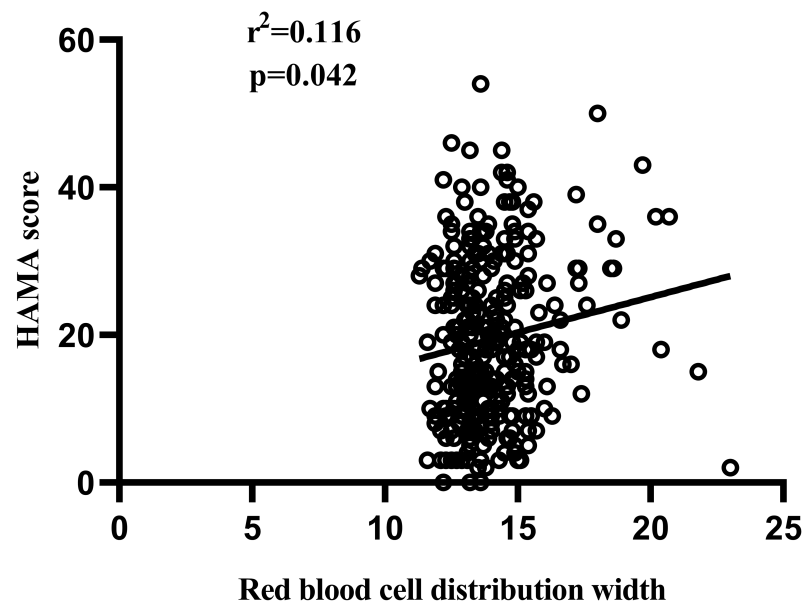

Figure 10 Correlation between red blood cell distribution width and the HAMA score.

conditions. On the one hand, with the condition of COPD progresses, the increasingly severe symptoms of hypoxia and dyspnea maybe the important causes of COPD with depression and/or depression; On the other hand, diseases coexisting with COPD, such as heart disease, gastroesophageal reflux disease, lung cancer, etc., also make the condition more poor and promote the occurrence of depression and/or anxiety in COPD. Furthermore, the greater the number of comorbidities in our study, the greater the risks of depression and/or anxiety (OR 2.144, 95\% CI 1.276-3.602) (Table 2). As far as smoking is concerned, there was no correlation with COPD combined with depression and/or anxiety. Initially, comparing the 


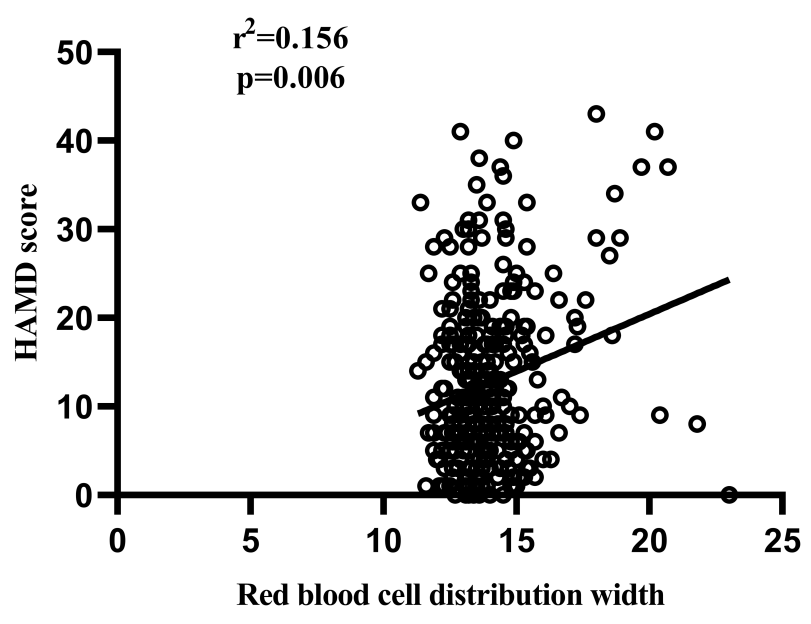

Figure I I Correlation between red blood cell distribution width and the HAMD score.

smoking history of the two groups of AECOPD patients, the result was that smoking was a protective factor in AECOPD combined with depression and/or anxiety (OR $0.496,95 \%$ CI $0.308-0.800$ ). It was speculated that the possible reason was related to the fact that the most nonsmokers were women, who account for a large proportion of depression and/or anxiety in AECOPD, and such results had occurred. Later, only the smoking history of the two groups of AECOPD was compared among men, and the difference between them was not statistically significant $(\mathrm{p}=0.765)$ (Table 2). After repeated comparisons, we still did not conclude that COPD patients with a history of smoking had a higher risk of depression and/or anxiety, which was not consistent with those obtained by other authors. $^{31,39-41}$ Next, inhaled glucocorticoid and home oxygen therapy were not associated with depression and/ or anxiety symptoms in AECOPD. From the data were collected, it can be found that the proportion of patients with AECOPD who inhaled glucocorticoids (12.1\%, 37 vs. $270)$ and received home oxygen therapy $(16.6 \%, 51$ vs. 256) were very low (Table 1). One reason was that most of the AECOPD patients included came from remote villages and lacked standardized diagnosis and treatment conditions, and the other reason was that the families cannot afford the oxygen equipment due to the limited economic conditions. Mention the effects of glucocorticoids on the mood of COPD patients, Hynninen et al. ${ }^{42,43}$ deem that glucocorticoid receptors in the hippocampus of the brain are activated by excessive glucocorticoids in the body, causing degeneration and necrosis of hippocampal neurons, which induce depression. Although it is known that glucocorticoid inhalation is unlikely to accumulate in the body, whether inhaled glucocorticoids in COPD patients also require oral or intravenous glucocorticoids during the period due to their serious conditions, resulting in chronic accumulation, which eventually led to depressed mood? In the present study, although the proportion of AECOPD patients inhaled glucocorticoids was very small, the most of the patients began to inhale glucocorticoids under the prescription of the physicians after this admission, and only very the few patients had been inhaled glucocorticoids irregularly in a short period at home. Therefore, it is difficult for us to quantify the inhaled glucocorticoids in the included AECOPD patients. After statistical analysis, there is no correlation between glucocorticoid inhalation and AECOPD combined with depression and/or anxiety. In terms of home oxygen therapy, long-term home oxygen therapy can improve the symptoms of hypoxia and dyspnea in COPD patients, which is beneficial to the quality of life and improve prognoses of them. However, due to the limitations of the economic conditions of the included AECOPD patients who can not receive long-term home oxygen therapy, which as a protective factor in COPD with depression and/or anxiety was not obtained in the study. The GOLD stages were compared among the AECOPD patients with spirometry results, and which was not associated with AECOPD combined with depression and/or anxiety ( $p=0.093$ ) (Table 1). It should be explained that that for the patients who failed to perform spirometry due to severe dyspnea symptoms and respiratory tract infection, after remission, the one part had too little hospitalization expenses to perform spirometry, and the other part had not due to their subjective wills to refuse. However, as can be seen from Table 1, among the AECOPD patients with GOLD4 and unable to perform spirometry, the patients with depression and/or anxiety account for more. Therefore, the correlation between the GOLD stages and AECOPD combined with depression and/or anxiety needs further study. Besides, Age, body mass index and duration of illness were related to COPD combined with depression and/or anxiety in some studies, but not in others and ours (Table 1). Perhaps they were considered as the risk factors that may vary across countries and across different cultural backgrounds within countries.

The negative impacts of depression and anxiety on COPD had been elaborated by many scholars. The GOLD guidelines have not formed a consensus on the diagnosis of COPD combined with depression and anxiety, both symptomatology and evaluation methods. Accordingly, it is very important to understand the distribution characteristics of 
depression and anxiety symptoms between COPD patients and depression and anxiety patients, to provide diagnostic ideas for clinical practices. In the comparison of the HAMA, both the total score of HAMA, the psychic anxiety factor and the somatic anxiety factor, the patients with depression and/ or anxiety showed higher scores, and there were significant statistical differences between them $(\mathrm{p}=0.000)$ (Table 4). It can be seen that the depression and/or anxiety group (35.8 \pm 6.95 ) showed severe anxiety, while the AECOPD with depression and/or anxiety group (25.83 \pm 8.35$)$ showed obvious anxiety, according to the HAMA scoring standard ( $\geq 21$ points, obvious anxiety; $\geq 29$ points, serious anxiety). In the HAMD comparison, the weight loss AECOPD combined with depression and/or anxiety group was more obvious $(\mathrm{p}=0.033)$; there was no statistical difference between the two groups of despair factor $(\mathrm{p}=0.194)$. In the total score of HAMD, anxiety/somatization, cognitive impairment, diurnal variation, retardation, sleep disorder, the differences between the two groups were statistically significant $(p=0.000)$ (Table $5)$. The most typical symptoms of depression in the Mental and Behavioral Disorders Classification (ICD-10) ${ }^{20}$ include: low mood, loss of interest and pleasure, and fatigue, and other symptoms include: self-guilt and sense of worthlessness, suicidal behaviors and ideas, sleep disorder and decreased appetite. These contents correspond to the depression factors in the HAMD scale: the sense of despair, cognitive impairment (self-guilt and sense of worthlessness, suicidal behaviors and ideas), anxiety/somatization (decreased appetite, fatigue), and retardation (low mood, loss of interest and pleasure, easy fatigue), sleep disorder. Except for the sense of despair, the scores of the other four depression factors in the depression and/or anxiety group were much higher than the counterpart $(p=0.000)$ (Table 5). Therefore, after comparing the characteristics of symptoms distribution between the two groups, as for COPD with depression and anxiety, in most cases, maybe a symptom rather than a disease.

The study of inflammation in COPD is an endless topic. More recent evidences highlighted the effect of inflammation on the mood of COPD, which was also one of the purposes of this study. In the healthy control group, the depression and/or anxiety group, the asymptomatic AECOPD group and the AECOPD with depression and/or anxiety group, WBC counts, RDW, NLR, PLR, and MLR were compared. The difference of PLR between the healthy control group and the depression and/or group was statistically significant $(\mathrm{p}<0.01)$ (Figure 8); the difference of RDW between the asymptomatic AECOPD group and the AECOPD with depression and/or anxiety group was statistically significant $(\mathrm{p}<0.05)$ (Figure $6)$. Remarkably, the five inflammatory markers of the two groups of AECOPD were much higher than the healthy control group and the depression and/or anxiety group respectively, and there were statistically significant differences among them $(\mathrm{p}<0.01)$. RDW was associated with the HAMA $\left(\mathrm{r}^{2}=0.116\right)$ and HAMD $\left(\mathrm{r}^{2}=0.156\right)$ (Figures 10 and 11) scores in AECOPD combined with depression and/or anxiety, and also had certain clinical diagnostic value (AUC $=0.570,95 \% \quad$ CI $0.513-0.626$ ) (Figure 4B). Neutrophils have long been viewed as the final effector cells that clear the body's pathogens during acute inflammation, and can produce a variety of anti-inflammatory molecules to promote inflammation absorption. ${ }^{44}$ The physiological response of the body to inflammation can lead to an increase in the number of neutrophils and a decrease in the number of lymphocytes. ${ }^{45,46}$ NLR, as an inflammatory marker, has been studied in many diseases including $\mathrm{COPD}^{47}{ }^{4}$ schizophrenia ${ }^{14}$ and various tumors in recent years, which is related to the prognosis and severity of COPD, kidney disease and cardiovascular disease. ${ }^{4,48-55}$ Likewise PLR, MLR and RDW are also used as inflammatory markers by scholars to study their relationship with inflammation. ${ }^{14,56,57}$ After entering the blood from the bone marrow, monocytes develop into macrophages and form a monocyte-macrophage system with macrophages in organs and tissues, and kill bacteria during body infection and release a variety of inflammatory cytokines, such as interleukin-1, interleukin-6, tumor necrosis factor, etc. On the one hand, some inflammatory mediators stimulate the proliferation of mononuclear macrophages, leading to an increase in platelets. When inflammation occurs, lymphocytes decrease, platelets increase, and the result of increased PLR appears; ${ }^{56}$ On the other hand, these cytokines can interfere with erythropoietin, affect the maturation of red blood cells, and increase the value of RDW; ${ }^{57}$ RDW shows the variability of circulating red blood cell size, which is a parameter reflecting the heterogeneity of red blood cell volume. Early RDW was mainly used in the diagnosis of anemia, but recent studies have shown that it is related to the prognoses of patients with pulmonary hypertension, congestive heart failure and coronary heart disease. ${ }^{58-60}$ Lippi et al ${ }^{59}$ suggested that RDW maybe related to potential chronic inflammation, due to the inflammatory cytokines inhibited the proliferation of erythroid progenitor cells by inhibiting endothelial nitric oxide production, which was considered to be a factor that stimulates erythroid progenitor cell proliferation, making RDW changed. In terms of the role of RDW in this study, 
we hypothesised that the increase of RDW in patients with AECOPD complicated with depression and/or anxiety may indicate more severe degree of inflammatory responses and significant inhibitory effects on the proliferation of red blood cell progenitor cells, thus affecting the parameters of changes in red blood cell size. However, this should be confirmed by more studies in the future. Otherwise, there was no correlation between NLR, PLR and MLR and AECOPD with depression and/or anxiety. Notably, this study found that the RDW, NLR, PLR, and MLR of the two groups of AECOPD were significantly higher than the other counterparts, with the significant statistical differences. Given the new understanding of these novel inflammatory markers in AECOPD, different from the other used inflammation indexes in the clinic, may provide more evidences of inflammation, and aid the clinicians in the determination of the severity of the AECOPD patient's condition and the risk of comorbidities. In particular, these novel inflammation markers obtained from complete blood counts widely used by clinicians, do not require additional costs, compared to the expensive inflammatory cytokines. For finding the difference between these novel inflammation markers and WBC counts in evaluating inflammation of AECOPD, WBC counts was used as a control parameter. Fortunately, they seem to have some similar roles with WBC counts. But these new inflammatory markers can be used as the common inflammatory indexes in the clinic need more further research to confirm. As for the correlation between PLR and depression and/or anxiety, which will be described in detail in the next article.

\section{Limitations}

This study has some limitations that should be mentioned. First, because of the overlaps of anxiety and depression symptoms in the items of the Hamilton Anxiety Rating Scale and the Hamilton Depression Rating Scale, the results were that the patients with anxiety may not have depression, but the patients with depression must have anxiety. It is worth noting that depression and anxiety are highly coexisting diseases with each other, anxiety is also one of the main symptoms of depression. So we could not compare patients who only had depression but no anxiety symptoms in this study, but put together patients with depression and/or anxiety. Second, the two AECOPD groups were older; the depression and anxiety group was younger and had most women. It needs to be explained is that the gender and age of the included healthy control group and the depression and/or anxiety group did not exactly match, despite age and gender have no effect on these inflammatory markers from the complete blood counts.

\section{Conclusions}

This study showed that a considerable proportion of AECOPD patients in hospital had depression and/or anxiety symptoms, and was closely related to the severity of the condition and quality of life. The CAT scale score was an important predictor and RDW had clinical diagnostic value in AECOPD combined with depression and/or anxiety. NLR, PLR, MLR, and RDW may become the novel indicators for evaluating the degree of inflammation of AECOPD and deserve further research.

\section{Acknowledgments}

The author would like to thank Zunyi Medical University for providing such a research platform, as well as the support and cooperation of all employees and patients. Special thanks to Mei Long for editing the video abstract.

\section{Funding}

This study was funded jointly by grants from the Zunyi City Science and Technology Cooperation Support Project NS (No. [2019]12), the National Natural Science Foundation of China (No. 81960016), the Basic Research Project of Guizhou Science and Technology Department, China (No. [2019]1349) and the Doctoral Research Initiation Fund of Zunyi Medical University (No. [2018]04).

\section{Disclosure}

The authors participating in this study stated that there was no conflict of interest.

\section{References}

1. American Lung Association Epidemiology and Statistics Unit. Trends in COPD (Chronic Bronchitis and Emphysema): morbidity and mortality; 2013. Available from: https://www.lung.org/assets/docu ments/research/copd-trend-report.pdf. Accessed October 14, 2018.

2. Mykletun A, Bjerkeset O, Øverland S, Prince M, Dewey M, Stewart R. Levels of anxiety and depression as predictors of mortality: the HUNT study. Br J Psychiatry. 2009;195(2):118-125. doi:10.1192/ bjp.bp. 108.054866

3. de Voogd JN, Wempe JB, Postema K, et al. More evidence that depressive symptoms predict mortality in COPD patients: is type D personality an alternative explanation? Ann Behavior Med. 2009;38(2):86-93. doi:10.1007/s12160-009-9105-8

4. Hynninen KM, Breitve MH, Wiborg AB, et al. Psychological characteristics of patients with chronic obstructive pulmonary disease: a review. J Psychosom Res. 2005;59:429-443. doi:10.1016/j.jpsych ores.2005.04.007 
5. Yohannes AM, Baldwin RC, Connolly MJ. Depression and anxiety in elderly outpatients with chronic obstructive pulmonary disease: prevalence, and validation of the BASDEC screening questionnaire. Int J Geriatr Psychiatry. 2000;15:1090-1096. doi:10.1002/10991166(200012)15:12<1090::AID-GPS249>3.0.CO;2-L

6. Shyam Chand Chaudhary SNAT. Prevalence of psychiatric comorbidities in chronic obstructive pulmonary disease patients. Lung India. 2016;2(32):174-178.

7. Putman-Casdorph H, McCrone S. Chronic obstructive pulmonary disease, anxiety, and depression: state of the science. Heart Lung. 2009;38(1):34-47. doi:10.1016/j.hrtlng.2008.02.005

8. Xu W, Collet JP, Shapiro S, et al. Independent effect of depression and anxiety on chronic obstructive pulmonary disease exacerbations and hospitalizations. Am J Respir Crit Care Med. 2008;178 (9):913-920. doi:10.1164/rccm.200804-6190C

9. Giardino ND, Curtis JL, Andrei A-C, et al. Anxiety is associated with diminished exercise performance and quality of life in severe emphysema: a cross-sectional study. Respir Res. 2010;11(1):29. doi:10.11 86/1465-9921-11-29

10. Ng T-P, Niti M, Tan W-C, Cao Z, Ong K-C, Eng P. Depressive symptoms and chronic obstructive pulmonary disease: effect on mortality, hospital readmission, symptom burden, functional status, and quality of life. Arch Intern Med. 2007;167(1):60-67. doi:10.1001/ archinte.167.1.60

11. Gudmundsson G, Gislason T, Janson C, et al. Risk factors for rehospitalisation in COPD: role of health status, anxiety and depression. Eur Respir J. 2005;26(3):414-419. doi:10.1183/09031936.05.00078 504

12. Al-Shair K, Kolsum U, Dockry R, et al. Biomarkers of systemic inflammation and depression and fatigue in moderate clinically stable COPD. Respir Res. 2011;12(1):3. doi:10.1186/1465-992112-3

13. Semiz M, Yildirim O, Canan F, et al. Elevated neutrophil/lymphocyte ratio in patients with schizophrenia. Psychiatr Danub. 2014;26 (3):220-225.

14. Özdin S, Bökeb Ö. Neutrophil/lymphocyte, platelet/lymphocyte and monocyte/lymphocyte ratios in different stages of schizophrenia. Psychiatry Res. 2018.

15. Global Initiative for Chronic Obstructive Lung disease. Strategy for the diagnosis, management and prevention of chronic obstructive pulmonary disease. 2019;31(EB/OL). Available from: https://gold copd.org/gold-report/. Accessed December 2, 2018.

16. Hurst JR, Wedzicha JA. What is (and what is not) a COPD exacerbation: thoughts from the new GOLD guidelines. Thorax. 2007;62 (3):198-199. doi:10.1136/thx.2007.077883

17. Wedzicha JA, Seemungal TA. COPD exacerbations: defining their cause and prevention. Lancet. 2007;370(9589):786-796. doi:10.1016/ S0140-6736(07)61382-8

18. Seemungal TA, Donaldson GC, Paul EA, Bestall JC, Jeffries DJ, Wedzicha JA. Effect of exacerbation on quality of life in patients with chronic obstructive pulmonary disease. Am J Respir Crit Care Med. 1998;157(5 Pt 1):1418-1422. doi:10.1164/ajrccm.157.5.970 9032

19. Burge S, Wedzicha JA. COPD exacerbations: definitions and classifications. Eur Respir J Suppl. 2003;41:46s-53s. doi:10.1183/ 09031936.03.00078002

20. Janca A, Ustün TB, Early TS, et al. The ICD-10 symptom checklist: a companion to the ICD-10 classification of mental and behavioural disorders. Soc Psychiatry Psychiatr Epidemiol. 1993;28(5):239-242. doi:10.1007/BF00788743

21. Wenbin C, Xianglin P. Diagnostics. People's Health Press; 2007:538.

22. Nianfeng G. Psychological Consultant. national press; 2005:179.

23. Bordoni B, Marelli F, Morabito B, et al. Depression,anxiety and chronic pain in patients with chronic obstructive pulmonary disease: the influence of breath. Monaldi Arch Chest Dis. 2017;87(1):811 $\square$. doi:10.4081/monaldi.2017.811
24. Jones P, Harding G, Wiklund I, et al. Improving the process and outcome of care in COPD: development of a standardised assessment tool. Prim Care Respir J. 2009;18:208-215. doi:10.4104/pcrj.2009.00053

25. Jones PW, Harding G, Berry P, et al. Development and first validation of the COPD assessment test. Eur Respir J. 2009;34:648-654. doi:10.1183/09031936.00102509

26. CAT Development Steering Group. COPD assessment test-healthcare professional user guide[J].[2014-05]. Available from: http://www.cateston line.org/images/UserGuides/CATHCPUser\%20guideEn.pdf, 2018. Acces sed January 31, 2011.

27. Dowson C, Laing R, Barraclough R, et al. The use of the Hospital Anxiety and Depression Scale (HADS) in patients with chronic obstructive pulmonary disease: a pilot study. $N Z$ Med J. 2001;114:447-449.

28. Di Marco F, Verga M, Reggente M, et al. Anxiety and depression in COPD patients: the roles of gender and disease severity. Respir Med. 2006;100:1767-1774. doi:10.1016/j.rmed.2006.01.026

29. Hanania NA, Mullerova H, Locantore NW, et al. Determinants of depression in the ECLIPSE chronic obstructive pulmonary disease cohort. Am J Respir Crit Care Med. 2011;183(5):604-611. doi:10.11 64/rccm.201003-0472OC

30. Xueli S. Psychiatry. Higher Education Press; 2013:325-326.

31. Pumar MI, Gray CR, Walsh JR, et al. Anxiety and depression-Important psychological comorbidities of COPD. J Thorac Dis. 2014;6(11):1615.

32. Kunik ME, Roundy K, Veazey C, et al. Surprisingly high prevalence of anxiety and depression in chronic breathing disorders. Chest. 2005;127:1205-1211. doi:10.1378/chest.127.4.1205.

33. Bosley CM, Corden ZM, Rees PJ, et al. Psychological factors associated with use of home nebulized therapy for COPD. Eur Respir J. 1996;9:2346-2350. doi:10.1183/09031936.96.09112346.

34. Gudmundsson G, Gislason T, Janson C, et al. Depression, anxiety and health status after hospitalisation for COPD: a multicentre study in the Nordic countries. Respir Med. 2006;100(1):87-93. doi:10.1016/j. rmed.2005.04.003

35. Mikkelsen RL, Middelboe T, Pisinger C, Stage KB. Anxiety and depression in patients with chronic obstructive pulmonary disease (COPD). A review. Nord J Psychiatry. 2004;58:66-70. doi:10.1080/ 08039480310000824

36. Almagro P, Barreiro B, Ochoa de Echaguen A, et al. Risk factors for hospital admissions in patients with chronic obstructive pulmonary disease. Respiration. 2006;73(3):311-317. doi:10.1159/ 000088092

37. Regvat J, Žmitek A, Vegnuti M, Košnik M, Šuškovič S. Anxiety and depression during hospital treatment of exacerbation of chronic obstructive pulmonary disease. J Int Med Res. 2011;39(3):10 28-1038. doi:10.1177/147323001103900338

38. Kim HF, Kunik ME, Molinari VA, et al. Functional impairment in COPD patients: the impact of anxiety and depression. Psychosomatics. 2010;41(6):465-471. doi:10.1176/appi.psy.41.6.465

39. Wiesbeck GA, Kuhl HC, Yaldizli O, et al. Tobacco smoking and depression-results from the WHO/ISBRA study. Neuropsychobiology. 2008;57:26-31. doi:10.1159/000123119

40. Mineur YS, Picciotto MR. Nicotine receptors and depression: revisiting and revising the cholinergic hypothesis. Trends Pharmacol Sci. 2010;31(12):580-586. doi:10.1016/j.tips.2010.09.004

41. Sinden NJ, Stockley RA. Systemic inflammation and comorbidity in COPD: a result of 'overspill' of inflammatory mediators from the lungs? Review of the evidence. Thorax. 2010;65(10):930-936. doi:10.1136/thx.2009.130260

42. Hynninen MJ, Pallesen S, Nordhus IH. Factors affecting health status in COPD patients with co-morbid anxiety or depression. Int J Chron Obstruct Pulmon Dis. 2007;2(3)::323-328.

43. Schneider B, Prvulovic D, Oertel -knochel V, et al. Biomarkers for major depression and its delineation from neurodegenerative disorders. Prog Neurobiol. 2011;95(4):703-717. doi:10.1016/j. pneurobio.2011.08.001 
44. Mantovani A, Cassatella MA, Costantini C, et al. Neutrophils in the activation and regulation of innate and adaptive immunity. Nat Rev Immunol. 2011;11(8):519-531

45. Zahorec R. Ratio of neutrophil to lymphocyte counts-Rapid and simple parameter of systemic inflammation and stress in critically ill. Bratisl Lek Listy. 2001;102(1):5-14.

46. Jager CPD, Wijk PTV, Mathoera RB. Lymphocytopenia and neutrophil-lymphocyte count ratio predict bacteremia better than conventional infection markers in an emergency care unit. Crit Care. 2010;14(5):R192. doi:10.1186/cc9309

47. Paliogiannis P, Fois AG, Sotgia S, et al. Neutrophil to lymphocyte ratio and clinical outcomes in COPD: recent evidence and future perspectives. Eur Respir Rev. 2018;7(147):170113. doi:10.1183/ 16000617.0113-2017

48. Williams KA, Labidi-Galy SI, Terry KL, et al. Prognostic significance and predictors of the neutrophil-to-lymphocyte ratio in ovarian cancer. Gynecol Oncol. 2014;132:542-550. doi:10.1016/j.ygyno.2014.01.026

49. Roxburgh CS, McMillan DC. Role of systemic inflammatory response in predicting survival in patients with primary operable cancer. Future Oncol. 2010;6(1):149-163. doi:10.2217/fon.09.136

50. Kacan T, Babacan NA, Seker M, et al. Could the neutrophil to lymphocyte ratio be a poor prognostic factor for non small cell lung cancers? Asian Pac J Cancer Prev. 2014;15(5):2089-2094. doi:10.7314/APJCP.2014.15.5.2089

51. Paliogiannis P, Scognamillo F, Bellomo M, et al. Neutrophil to lymphocyte ratio as a predictor of thyroid papillary carcinoma. Act Med Mediterr. 2015;31:371-375.

52. Azab B, Bhatt VR, Phookan J, et al. Usefulness of the neutrophil-tolymphocyte ratio in predicting short- and long-term mortality in breast cancer patients. Ann Surg Oncol. 2012;19(1):217-224. doi:10.1245/s10434-011-1814-0
53. Stotz M, Gerger A, Eisner F, et al. Increased neutrophil-lymphocyte ratio is a poor prognostic factor in patients with primary operable and inoperable pancreatic cancer. Br J Cancer. 2013;109(2):416-421. doi:10.1038/bjc.2013.332

54. Duffy BK, Gurm HS, Rajagopal V, et al. Usefulness of an elevated neutrophil to lymphocyte ratio in predicting long-term mortality after percutaneous coronary intervention. Am J Cardiol. 2006;97:993-996. doi:10.1016/j.amjcard.2005.10.034

55. Arbel Y, Finkelstein A, Halkin A, et al. Neutrophil/lymphocyte ratio is related to the severity of coronary artery disease and clinical outcome in patients undergoing angiography. Atherosclerosis. 2012;225 (2):456-460. doi:10.1016/j.atherosclerosis.2012.09.009

56. Bosch F, Ribes J, Borràs J. Epidemiology of Primary Liver Cancer. Semin Liver Dis. 1999;19(03):271-285. doi:10.1055/s-2007-1007117

57. Pierce CN, Larson DF. Inflammatory cytokine inhibition of erythropoiesis in patients implanted with a mechanical circulatory assist device. Perfusion. 2005;20(2):83-90. doi:10.1191/0267659105pf7 93 oa

58. Hampole CV, Mehrotra AK, Thenappan T, Gomberg-Maitland M, Shah SJ. Usefulness of red cell distribution width as a prognostic marker in pulmonary hypertension. Am J Cardiol. 2009;104 (6):868-872. doi:10.1016/j.amjcard.2009.05.016

59. Lippi G, Targher G, Montagnana M, et al. Relation between red blood cell distribution width and inflammatory biomarkers in a large cohort of unselected outpatients[J]. Archives of pathology\&laboratory medicine, 2009,133(4):628-632.

60. Tonelli M, Sacks F, Arnold M, Moye L, Davis B, Pfeffer M; for the Cholesterol and Recurrent Events (CARE) Trial Investigators. Relation between red blood cell distribution width and cardiovascular event rate in people with coronary disease. Circulation. 2008;117 (2):163-168. doi:10.1161/CIRCULATIONAHA.107.727545

\section{Publish your work in this journal}

The International Journal of COPD is an international, peer-reviewed journal of therapeutics and pharmacology focusing on concise rapid reporting of clinical studies and reviews in COPD. Special focus is given to the pathophysiological processes underlying the disease, intervention programs, patient focused education, and self management protocols. This journal is indexed on PubMed Central, MedLine and CAS. The manuscript management system is completely online and includes a very quick and fair peer-review system, which is all easy to use. Visit http://www.dovepress.com/testimonials.php to read real quotes from published authors. 